\title{
Multiplexed tandem mass spectrometry-based screening for five lysosomal storage disorders: A pilot study
}

\author{
Manjunath Supriya', (1) Rita Christopher', (1) Chandra Sadanandavalli Retnaswami
}

'Department of Neurochemistry, National Institute of Mental Health And Neuro Sciences, Bengaluru, India

${ }^{2}$ Department of Neurology, National Institute of Mental Health And Neuro Sciences, Bengaluru, India

\begin{abstract}
Objectives: The need for early detection of lysosomal storage diseases (LSDs) for which therapeutic options are available makes them attractive candidate disorders to perform high-throughput population screening. This is a pilot study designed to simultaneously screen for Krabbe, Niemann-Pick types A/B, Fabry, Gaucher and Pompe diseases in putatively normal Indian subjects, using dried blood spots and a liquid chromatography-tandem mass spectrometry method.

Methods: Blood spots from 12,559 putatively normal subjects were used to measure 5 lysosomal enzymes: galactocerebrosidase, acid sphingomyelinase, $a$-galactosidase, $\beta$-glucocerebrosidase, and a-glucosidase. From each blood spot, 3.2-mm punches were extracted and incubated using specific substrates and internal standards. After several liquid- and solid-phase extraction steps, the resulting solution was reconstituted and injected into a triple quadrupole, liquid chromatography-tandem mass spectrometer after recombining the reaction products into a single 96-well plate. Results: A standard calibration curve demonstrated good linearity for each enzyme. No positive case was detected among the 12,559 putatively normal subjects tested.

Conclusion: Tandem mass spectrometry technology makes it possible to perform high-throughput screening to identify LSDs using blood spots. Further large-scale studies to determine the population prevalence and incidence of these disorders are warranted.

Keywords: Dried blood spots, lysosomal storage disorders, screening, tandem mass spectrometry
\end{abstract}

ysosomal storage diseases (LSDs) are rare individually, with Lan overall reported incidence of 1 in 1500-7000 live births [1]. Despite the relative rarity of LSDs, recent technological advances and therapeutic possibilities have expanded the scope of newborn screening programs to include treatable LSDs. Classic LSDs are a group of inherited disorders generally caused by the lack of a functional lysosomal enzyme, which results in the progressive accumulation of metabolites in the lysosomes [2]. LSDs are usually asymptomatic at birth and are characterized by clinical manifestations affecting multiple organs and systems in the body [3]. Clinical treatment is available for specific LSDs, and includes enzyme replacement therapy $[4,5]$, hematopoietic stem cell transplantation
[6], chemical chaperone therapy, and substrate reduction therapy [7]. The efficacy of many proposed therapies relies heavily upon the initiation of treatment before the onset of irreversible pathologies; therefore, early detection of these diseases before symptom onset is crucial to improving clinical outcomes following specific therapy.

Li et al. [8] first described a novel approach for simultaneous estimation of several lysosomal enzyme activities related to LSDs (Fabry, Gaucher, Krabbe, Niemann-Pick A/B, and Pompe diseases) in dried blood spots (DBSs) using tandem mass spectrometry (MS/MS). Gelb et al. [9] optimized the assay method using electrospray ionization-MS/MS to measure the activity of lysosomal enzymes. Subsequently, several studies

Address for correspondence: Rita Christopher, MD. Department of Neurochemistry, National Institute of Mental Health And Neuro Sciences, Bengaluru, India Phone: 91-80-26995163 E-mail: rita.nimhans@yahoo.com ORCID: 0000-0002-0024-4748

Submitted Date: March 03, 2020 Accepted Date: April 11, 2020 Available Online Date: April 29, 2020

${ }^{\circ}$ Copyright 2020 by International Journal of Medical Biochemistry - Available online at www.internationalbiochemistry.com OPEN ACCESS This work is licensed under a Creative Commons Attribution-NonCommercial 4.0 International License. 
focused on adapting liquid chromatography-tandem mass spectrometry (LC-MS/MS) technology with new substrates and internal standards to modify and develop methods for mass screening of LSDs using DBS samples [10, 11]. LC-MS/ MS-based assays are not only suitable for high-throughput population screening, but also allow the assessment of multiple LSDs simultaneously in a single process using a DBS specimen. Quite recently, pilot newborn screening projects have been implemented in many developed countries using MS/MS technology to detect specific LSDs [12-17]. In India however, population or newborn screening for LSDs has not been introduced and the use of LC-MS/MS for LSD screening has not been evaluated.

In this pilot program, a triple-quadrupole LC-MS-MS was used to simultaneously measure 5 lysosomal enzymes: galactocerebrosidase (GALC), acid sphingomyelinase (ASM), a-galactosidase (GLA), $\beta$-glucocerebrosidase (GBA), and a-glucosidase (GAA) in DBS samples from putatively normal subjects. $A$ total of 12,559 blood samples were screened using this assay method to evaluate the feasibility of introducing LC-MS/MSbased mass screening in India.

\section{Materials and Methods}

This study was approved by the Institutional Ethics Committee of the National Institute of Mental Health and Neuro-Sciences, Bengaluru, India, and complied with the World Medical Association Declaration of Helsinki regarding the ethical conduct of research involving human subjects.

\section{Screening for LSDs in DBS samples}

Informed consent was obtained from all of the participants and the parents of children enrolled in the study. Leftover DBS samples of putatively normal individuals received in the Metabolic Laboratory of the National Institute of Mental Health and Neuro-Sciences, Bengaluru, India for routine testing during the 3 years (2011-2014) of the pilot study were analyzed. All of the samples were completely dried at room temperature for 4 hours, stored with desiccant at $-80^{\circ} \mathrm{C}$ in re-sealable plastic zipper storage bags, and analyzed within a week of sampling. In all, 12,559 samples were tested. The subjects were divided into 4 groups based on age: 3507 newborns [mean age: 14.33 days, females $=1320$ (mean age: 14.02 days) and males=2187 (mean age: 14.52 days)], 2940 infants [mean age: 7.28 months, females $=1097$ (mean age: 7.39 months) and males=1843 (mean age: 7.21 months)], 5654 children [mean age: 5.58 years, females $=2127$ (mean age: 5.42 years) and males 3527 (mean age:5.68 years)] and 458 adults [mean age: 30.57 years, females $=183$ (mean age: 29.32 years) and males $=275$ (mean age:31.40 years)]. The 0.5 th and 99.5 th percentiles were used as the cut-off values to identify positive cases. Samples with values below the defined cut-off were reanalyzed 3 times in subsequent analysis. The screening results were confirmed by measuring the en- zyme activity in peripheral blood leukocytes using a fluorometric assay [18].

\section{LSD MS/MS multiplex assay cocktail}

The substrate (S) and internal standards (IS) for the 5 lysosomal enzymes were as follows: GALC, GALC-S, and GALC-IS for Krabbe disease; ASM, ASM-S, and ASM-IS for Niemann-Pick A/B disease; GLA, GLA-S, and GLA-IS for Fabry dis ᄀease; GBA, GBA-S, and GBA-IS for Gaucher disease; and GAA, GAA-S, and GAA-IS for Pompe disease. These materials were received from the Centers for Disease Control and Prevention Foundation of Atlanta, Georgia, USA. The details of assay cocktail components and preparation have been described previously [19]. All of the chemicals and reagents used for analysis were of high-purity grade and were purchased from Sigma-Aldrich Corp. (St. Louis, MO, USA).

\section{DBS specimens for quality control}

DBS samples with base, low, medium, and high enzyme activity for GALC, ASM, GLA, GBA, and GAA were provided by the Newborn Screening Translation Research Initiative of the CDC Foundation (Atlanta, GA, USA). For every run or assay reaction, samples were run in duplicates along with the appropriate blanks, 2 control samples from healthy individuals, as well as positive control samples from affected patients, for method validation.

\section{Determination of enzyme activity}

The method of determination of the enzyme activity for the 5 LSDs has been described previously [19]. Briefly, the enzymes were extracted from a DBS punch in a sodium phosphate buffer (70uL) for 1 hour at $37^{\circ} \mathrm{C}$. Enzyme extracts were incubated with specific substrates in a 96-well plate for 2024 hours at $37^{\circ} \mathrm{C}$ and then terminated with $100 \mathrm{uL}$ of ethyl acetate:methanol solution. The assay reaction mixture was pooled, followed by the addition of 400uL of ethyl acetate and $400 \mathrm{uL}$ of high performance liquid chromatography-grade water (liquid extraction). The top organic layer was later dried under a stream of nitrogen. After reconstitution with ethyl acetate-methanol, the samples were subjected to a solid phase extraction, dried under nitrogen, sealed and stored at $-20^{\circ} \mathrm{C}$ until analysis. Prior to MS/MS analysis, the plates were thawed and reconstituted with 200uL of acetonitrile:water containing formic acid.

\section{Chromatographic conditions}

The chromatographic system used in the study was a Waters Alliance 2795 UPLC (Waters Corp., Milford, MA, USA). Separation of the reaction products of multiplex LSD enzyme assays was determined using a Waters $\mathrm{C} 18$ analytical column $(3.5 \mu \mathrm{M}$, $2.1 \times 50 \mathrm{~mm}$; Waters Corp., Milford, MA, USA) maintained at $35^{\circ} \mathrm{C}$ via a flow rate of $0.2 \mathrm{~mL} /$ minute. The mobile phase consisted of 
acetonitrile:water (80:20, v/v) with $0.2 \%$ formic acid. The total run time was 2 minutes with an injection volume of $20 \mathrm{uL}$.

\section{Tandem mass spectrometry conditions}

Detection of enzyme reaction products was achieved using a triple quadrupole tandem mass spectrometer (MS/MS Quattro Micro Research System; Waters Corp., Milford, MA, USA) with electrospray ionization (ESI) operated in positive mode. The 5 products and their respective internal standards (IS) were monitored using selected-reaction monitoring transitions with a source temperature of $100^{\circ} \mathrm{C}$ and a desolvation temperature of $250^{\circ} \mathrm{C}$. Details of the MS/MS parameters are described in Table 1. Data acquisition, peak integration, and analysis were performed using MassLynx version 4.1 software (Waters Corp., Milford, MA, USA). The enzyme activity of each sample was calculated from the ion abundance ratio of product to IS measured by MS. The enzyme activity was expressed in $\mu \mathrm{mol} / \mathrm{h} / \mathrm{L}$ and calculated from the amount of product by assuming that a 3.2-mm DBS disk contained $3.2 \mu \mathrm{L}$ of blood.

\section{Validation (linearity, precision and accuracy)}

The linearity of the method was evaluated to determine the linear reportable range of each test analyte. Evaluation of this analysis was achieved through the use of slopes, intercept, and the correlation coefficient obtained from constructing calibration curves using a series of liquid calibrators with the substrate and IS for each enzyme in predefined ratios (P/IS: 0 , $0.10,0.50,1.0,2.0$, and 5.0 ). To evaluate intra-assay precision, the enzyme activity of the CDC QC samples were measured 5 times at low, medium, and high concentrations within the same assay run. The same CDC samples were run in triplicate 15 consecutive times to determine the inter-assay coefficient

Table 1. Mass spectrometer parameters during the analysis of lysosomal enzymes

\begin{tabular}{ll}
\hline Parameters & Value \\
\hline Source temperature $\left({ }^{\circ} \mathrm{C}\right)$ & 100 \\
Desolvation temperature $\left({ }^{\circ} \mathrm{C}\right)$ & 250 \\
Capillary voltage $(\mathrm{kV})$ & 3 \\
Cone gas flow $(\mathrm{L} / \mathrm{h})$ & 50 \\
Desolvation gas flow $(\mathrm{L} / \mathrm{h})$ & 800 \\
Low mass resolution 1 & 15 \\
High mass resolution 1 & 15 \\
lon energy 1 & 0.5 \\
Collision cell entrance potential $(\mathrm{V})$ & 2 \\
Collision cell exit potential $(\mathrm{V})$ & 2 \\
Low mass resolution 2 & 14 \\
High mass resolution 2 & 14 \\
lon energy 2 & 2 \\
Polarity & $\mathrm{ES}+$ \\
Collision gas & $\mathrm{Ar}$ \\
Desolvation gas & $\mathrm{N} 2$
\end{tabular}

of variation. The accuracy was evaluated by comparing the enzymatic activity obtained in quality control (QC) DBSs with the results predetermined by the CDC.

\section{Statistical analysis}

Statistical analyses were performed using GraphPad Prism v.5.0.1 (GraphPad Software Inc., La Jolla, CA, USA). Intra-assay and inter-assay $\mathrm{CV}$ results were expressed as mean $\pm \mathrm{SD}$.

\section{Results}

\section{Development of high throughput multiplex assay for screening of LSDs}

Chromatographic separation of the reaction products and mass spectrometric conditions (capillary voltage, cone voltage, collision energy, etc.) for electrospray ionization and the multiple reaction monitoring (MRM) of the product (P) and IS for multiplex LSD assay were optimized. MRM transitions of the $\mathrm{P}$ and IS are listed in Table 2.

\section{Linearity}

Calibration curves for GALC, ASM, GLA, GBA, and GAA at different $\mathrm{P} / \mathrm{IS}$ ratios $(0,0.05,0.10,0.50,1.0,2.0)$ showed reproducible signals, good linear responses, and correlation coefficient $R^{2}$ (GAA: $R^{2}=0.999 ; \mathrm{GLA}: \mathrm{R}^{2}=0.998 ; \mathrm{GBA}: \mathrm{R}^{2}=0.999 ; \mathrm{ASM}: \mathrm{R}^{2}=0.998$; GALC: $\left.R^{2}=0.999\right)$. Data for calibration standards and linearity are listed in Table 3 . The calibration curves for 5 LSD analytes are shown in Figure 1.

\section{Quality control and validation}

The precision of enzyme activity was determined according to the Clinical and Laboratory Standards Institute guidelines

Table 2. Conditions for tandem mass spectrometry and multiple reaction monitoring transitions of the products and internal standards

\begin{tabular}{llll}
\hline Analytes & $\begin{array}{l}\text { MRM } \\
\text { transition, } \mathbf{~ m / z}\end{array}$ & $\begin{array}{l}\text { Cone } \\
\text { voltage, } \mathbf{~}\end{array}$ & $\begin{array}{l}\text { Collision } \\
\text { energy, eV }\end{array}$ \\
\hline GAA-IS & $503.25-403.28$ & 15 & 20 \\
GAA-P & $510.45-264.28$ & 15 & 20 \\
GLA-IS & $489.25-389.25$ & 25 & 20 \\
GLA-P & $498.25-398.25$ & 15 & 20 \\
GBA-IS & $484.15-384.25$ & 25 & 20 \\
GBA-P & $482.40-264.28$ & 15 & 20 \\
ASM-IS & $370.25-264.25$ & 15 & 20 \\
ASM-P & $398.25-264.25$ & 15 & 20 \\
GALC-IS & $454.30-264.25$ & 15 & 20 \\
GALC-P & $426.30-264.25$ & 15 & 20
\end{tabular}

ASM: Acid sphingomyelinase; GAA: a-glucosidase; GALC: Galactocerebrosidase; GBA: $\beta$-glucocerebrosidase; GLA: a-galactosidase; IS: Internal standards; MRM: Multiple reaction monitoring; P: Product. 
Table 3. Calibration results and linearity parameters

\begin{tabular}{llllll}
\hline Ratio P/IS & $\begin{array}{l}\text { GAA, Observed } \\
\text { ratio }\end{array}$ & $\begin{array}{l}\text { GLA, Observed } \\
\text { ratio }\end{array}$ & $\begin{array}{l}\text { GBA, Observed } \\
\text { ratio }\end{array}$ & $\begin{array}{l}\text { ASM, Observed } \\
\text { ratio }\end{array}$ & $\begin{array}{l}\text { GALC, Observed } \\
\text { ratio }\end{array}$ \\
\hline 0 & 0 & 0 & 0.002 & 0.001 & 0.002 \\
0.05 & 0.046 & 0.052 & 0.057 & 0.053 & 0.049 \\
0.1 & 0.093 & 0.095 & 0.109 & 0.107 & 0.099 \\
0.5 & 0.48 & 0.483 & 0.544 & 0.507 & 0.506 \\
1 & 0.92 & 0.934 & 1.095 & 1.014 & 0.979 \\
2 & 1.844 & 1.816 & 2.161 & 1.941 & 1.942 \\
5 & 4.471 & 4.517 & 5.286 & 4.776 & 4.906 \\
$R^{2}$ & 0.999 & 0.998 & 0.999 & 0.998 & 0.999 \\
Slope & 0.924 & 0.935 & 1.076 & 0.999 & 0.979 \\
\hline
\end{tabular}

ASM: Acid sphingomyelinase; GAA: a-glucosidase; GALC: Galactocerebrosidase; GBA: $\beta$-glucocerebrosidase; GLA: $\alpha$-galactosidase; IS: Internal standards; P: Product.

[20]. Accuracy and precision of the technique were evaluated by assaying the QC samples provided by the CDC (high, medium, low, and baseline) containing 100, 50, 5, and 0\% control enzyme activity. As shown in Table 4, the measured mean enzyme activity assayed 15 consecutive times was comparable to the enzyme activity reported by the CDC.

The intra-assay precision and inter-assay precision of GAA, GLA, GBA, ASM, and GALC activity for each CDC QC sample at each level is provided in Table 5. The intra- and inter-run CV was between 1.26 and $8.88 \%$ and between 5.32 and $18.31 \%$, respectively, for the activity of the 5 enzymes studied.

\section{Determination of enzyme activity in the DBS}

A total of 12,559 putatively normal subjects were screened for 5 LSDs. The enzyme activity of these participants (new-

Table 4. Comparison of enzyme activity ( $\mu \mathrm{mol} / \mathrm{L} / \mathrm{h})$ in quality control dried blood spots determined by the study lab and the US Centers for Disease Control and Prevention

\begin{tabular}{|c|c|c|c|c|c|}
\hline & GAA & GBA & GLA & ASM & GALC \\
\hline Base pool & $0.57 \pm 0.07$ & $0.55 \pm 0.10$ & $1.11 \pm 0.14$ & $0.21 \pm 0.02$ & $0.11 \pm 0.01$ \\
\hline Medium & $5.50 \pm 0.65$ & $5.83 \pm 0.71$ & $7.83 \pm 0.38$ & $1.42 \pm 0.16$ & $4.33 \pm 0.34$ \\
\hline High & $13.38 \pm 1.58$ & $12.45 \pm 0.98$ & $14.69 \pm 1.74$ & $3.00 \pm 0.20$ & $6.71 \pm 0.35$ \\
\hline Low & $(0.47-1.02)$ & $(0.19-0.90)$ & $(0.19-1.23)$ & $(0.10-0.40)$ & $(0.26-0.43)$ \\
\hline Medium & $(5.42-7.83)$ & (3.93-6.29) & $(4.60-6.88)$ & $(1.25-1.96)$ & $(2.36-3.48)$ \\
\hline High & $(10.14-15.63)$ & $(7.03-12.35)$ & (8.01-14.09) & $(2.33-3.70)$ & $(4.95-6.83)$ \\
\hline
\end{tabular}

ASM: Acid sphingomyelinase; CDC: US Center for Disease Control and Prevention; CI: Confidence interval; GAA: a-glucosidase; GALC: Galactocerebrosidase; GBA: $\beta$-glucocerebrosidase; GLA: a-galactosidase; QC: Quality control.

Table 5. Intra- and inter-assay coefficients of variation of the US Center for Disease Control and Prevention quality control samples for 5 lysosomal enzymes

\begin{tabular}{|c|c|c|c|c|c|c|c|c|c|c|}
\hline CDC QC & \multicolumn{5}{|c|}{ Intra-assay precision (CV\%), $\mathrm{n}=5$} & \multicolumn{5}{|c|}{ Inter-assay precision (CV\%), n=15 } \\
\hline Base pool & 7.09 & 5.85 & 8.88 & 2.54 & 4.40 & 12.61 & 18.31 & 12.78 & 6.78 & 8.88 \\
\hline Low & 4.01 & 6.33 & 3.97 & 4.54 & 2.27 & 16.67 & 14.65 & 6.66 & 11.39 & 6.25 \\
\hline Medium & 2.15 & 3.04 & 1.26 & 4.22 & 6.04 & 11.92 & 12.4 & 4.92 & 15.00 & 8.09 \\
\hline High & 5.66 & 3.94 & 5.95 & 5.98 & 2.83 & 11.85 & 7.87 & 11.86 & 12.59 & 5.32 \\
\hline
\end{tabular}

ASM: Acid sphingomyelinase; CDC: US Center for Disease Control and Prevention; CV: Coefficient of variation; GAA: a-glucosidase; GALC: Galactocerebrosidase; GBA: $\beta$-glucocerebrosidase; GLA: a-galactosidase; QC: Quality control. 


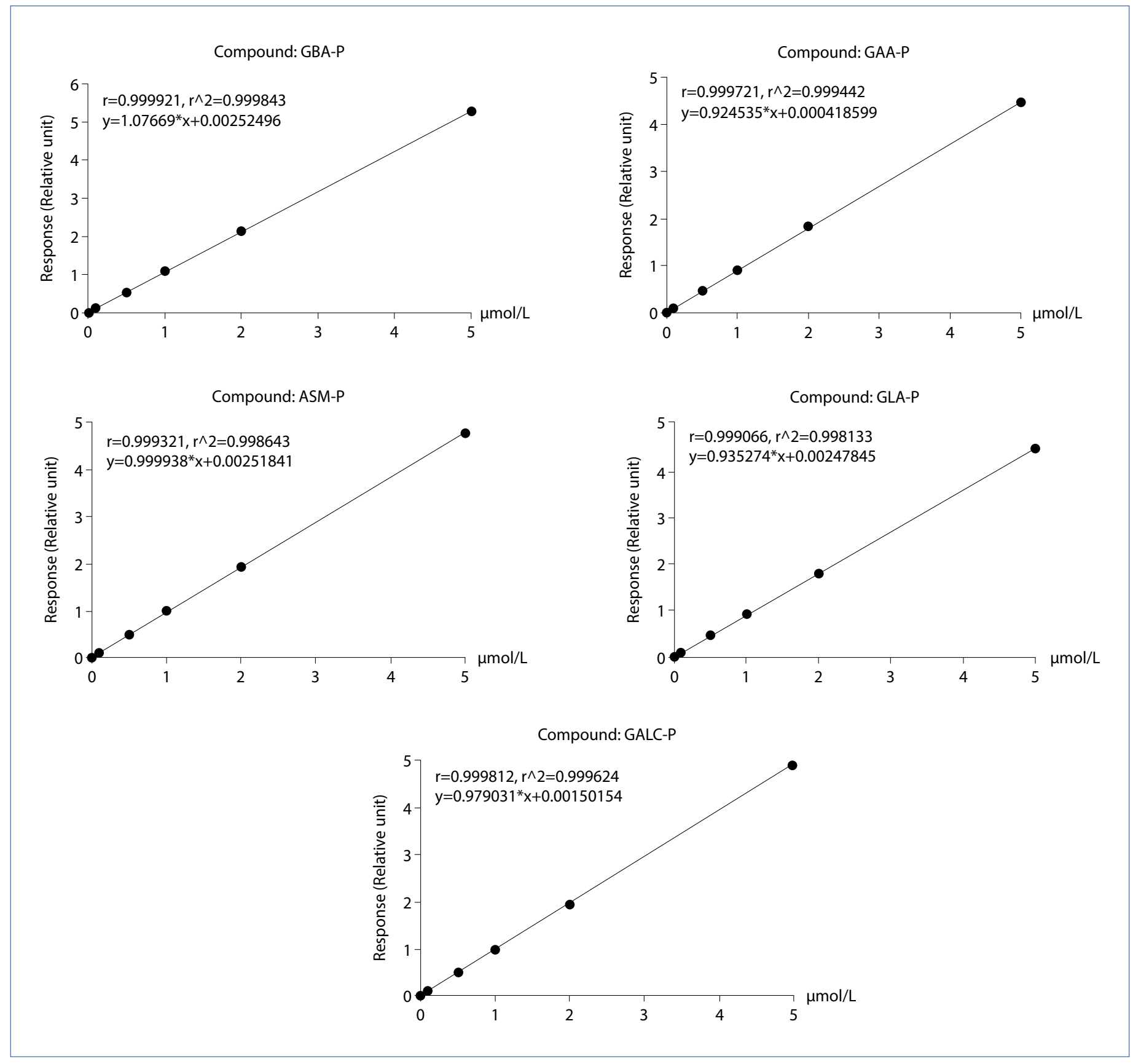

Figure 1. The linearity of the internal standards of all 5 enzyme assays analyzed. The enzyme activity is expressed in $\mu \mathrm{mol} / \mathrm{h} / \mathrm{L}$ and calculated from the amount of product by assuming that a 3.2-mm dried blood spot disk contained $3.2 \mu \mathrm{L}$ of blood.

ASM: Acid sphingomyelinase; GAA: a-glucosidase; GALC: Galactocerebrosidase; GBA: $\beta$-glucocerebrosidase; GLA: $\alpha$-galactosidase; P: Product.

borns, infants, children, and adults) is represented in Figure 2. Low enzyme activity (samples with less than 0.5 percentile activity) for GAA were found in $31(0.25 \%)$, for GBA in $21(0.17 \%)$, for ASM in $19(0.15 \%)$, for GLA in $49(0.39 \%)$, and GALC in $36(0.29 \%)$ samples. These 156 samples were subjected to retesting in triplicate. The white blood cell enzyme results are presented in Supplementary Table 1. After second-tier testing of the lysosomal enzymes in peripheral blood leukocytes with fluorometric assays, no positive case with an LSD was detected.

\section{Discussion}

The availability of disease-specific therapies and the possibility that early intervention may lead to improved patient outcome is paving way for routine screening of several LSDs. The diagnosis of an LSD requires the demonstration of a deficiency of the relevant enzyme in peripheral blood leukocytes or fibroblasts [21]. The recent development of electrospray MS/MS [9] has made it possible to use a single test of DBS to screen for multiple disorders with high sensitivity and specificity. Con- 


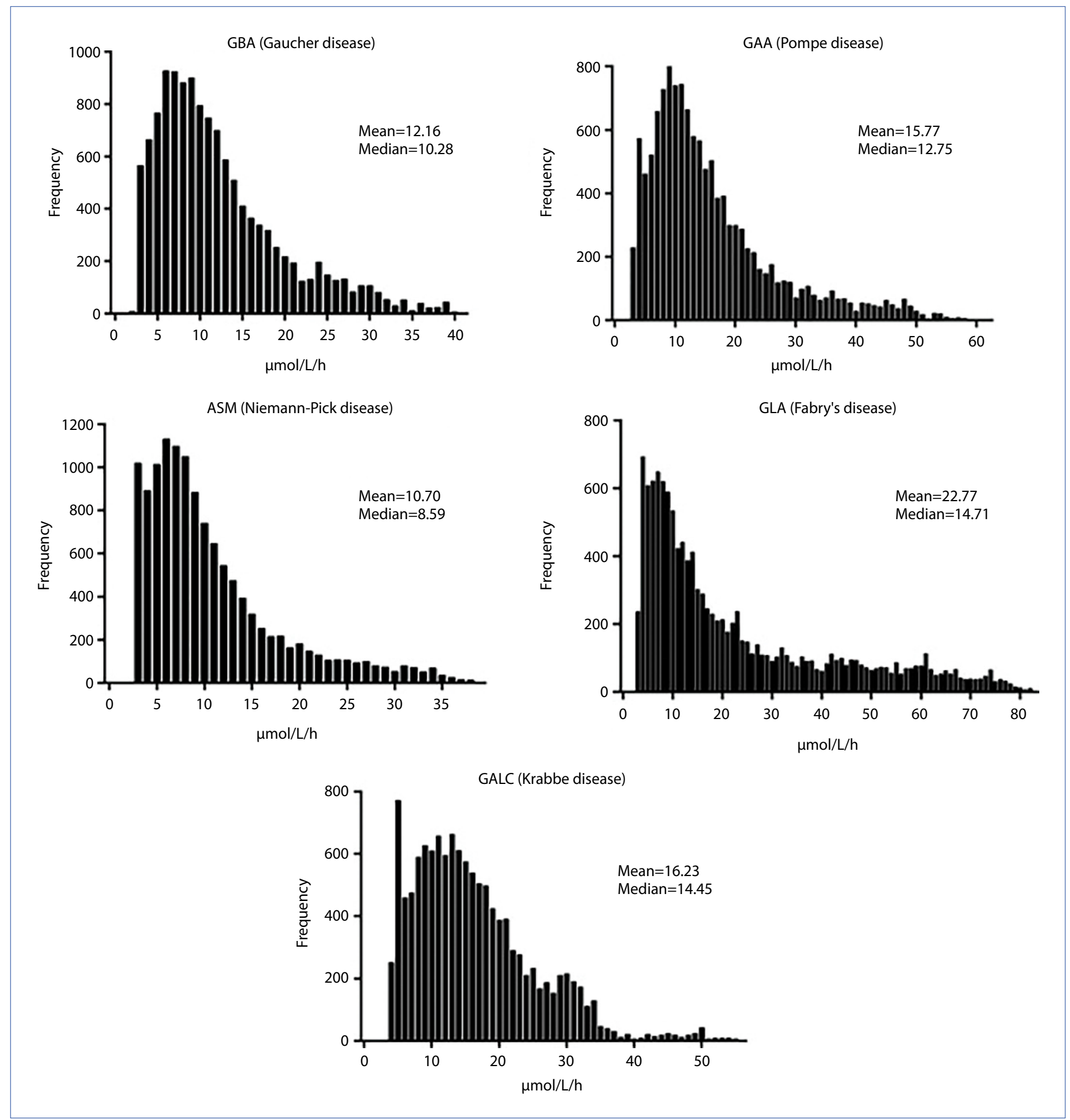

Figure 2. Histogram representation and statistical data of the distribution of lysosomal enzyme activity in the study participants.

ASM: Acid sphingomyelinase; GAA: a-glucosidase; GALC: Galactocerebrosidase; GBA: $\beta$-glucocerebrosidase; GLA: $\alpha$-galactosidase.

sequently, several pilot studies have focused on multiplexed LC-MS/MS enzyme assay for high-throughput screening for various LSDs in newborn DBS [8-10]. Such studies have not yet been conducted in India, although the prevalence of LSDs is expected to be high due to a high occurrence of consanguinity among certain communities [22]. Screening of selected, clinically suspected high-risk cases in various referral laboratories with fluorometric or spectrophotometric assays have found a spectrum of LSDs in India [23-26]. Thus, in this study, we used the multiplex LC-MS/MS methodology for the screening and identification of 5 LSDs (Krabbe, Niemann-Pick types A/B, Fabry, Gaucher, and Pompe diseases) using DBS samples 


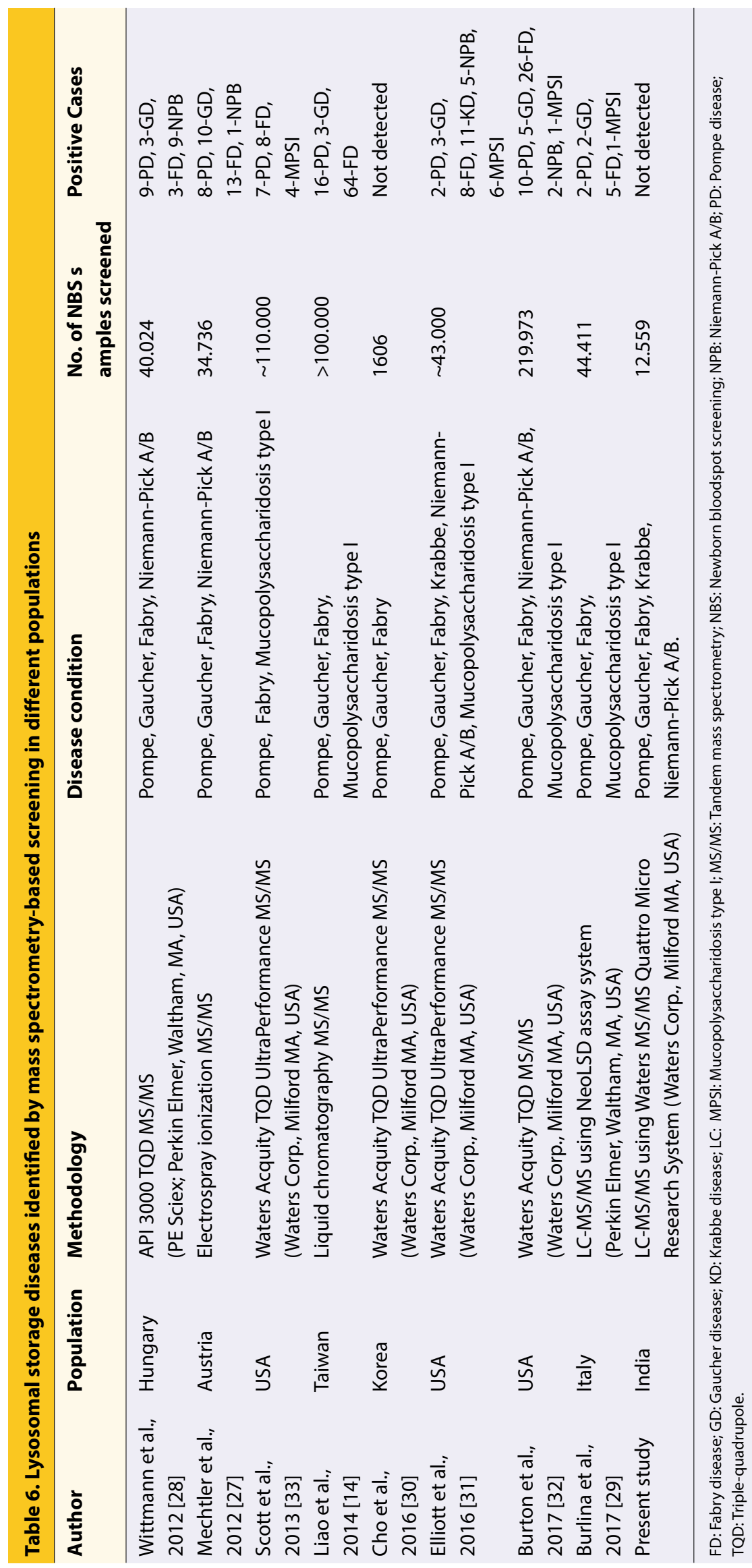




\begin{tabular}{|c|c|c|c|c|}
\hline a-glucosidase (GAA) & 31 & $\mathrm{Nil}$ & $12.65 \pm 1.27$ & $5.0-22.8$ \\
\hline$\beta$-glucocerebrosidase (GBA) & 21 & Nil & $9.83 \pm 2.38$ & $4.2-13.1$ \\
\hline a-galactosidase (GLA) & 49 & Nil & $27.65 \pm 3.87$ & $15.4-32.6$ \\
\hline
\end{tabular}

Nil: Zero positive cases detected. *Age appropriate reference values.

collected from putatively normal subjects. The data obtained from the slope of the linearity curve of the P/IS ratio for the calibrators for each analyte during method validation showed detectable and reproducible signals and linear response (Table 3). The enzyme activity in quality control DBS samples was within the acceptable range as reported by the $C D C$, and the panel of QC samples was clearly able to differentiate between them with good accuracy for all analytes. Additionally, the repeatability of the LC-MS/MS method on QC DBS samples was reliable, as the intra-assay and inter-assay $C V$ was less than $9 \%$ and $18 \%$, respectively. We did not detect any positive case of Krabbe, Niemann-Pick types A/B, Fabry, Gaucher, or Pompe disease in the 12,559 subjects tested.

As part of a routine national Austrian newborn screening program, Mechtler et al. [27] analyzed DBSs of 34,736 newborns for ASM, GLA, GAA, and GBA activity using electrospray ionization MS/MS and reported a prevalence of Gaucher disease at 1:17368, Pompe disease at 1:8684 and Fabry disease at 1:3859 births. In a Hungarian newborn screening program, Wittmann et al. [28] identified 3 cases of Gaucher disease, 3 cases of Fabry disease, 9 cases of Pompe, and 2 cases with Niemann-Pick A/B on screening 40,024 samples using MS/MS. A study from Northeast Italy reported an incidence of Pompe and Gaucher diseases as 1:22.205, with Fabry disease being the most common (1:8882) and Mucopolysaccharidosis I, the rarest (1:44.411) in 44,411 newborns screened for 4 LSDs using NeoLSD assay system (PE Sciex; Perkin Elmer, Waltham, MA, USA) [29]. In contrast, Cho et al. [30] found no positive cases of Pompe, Gaucher, or Fabry disease in 1606 anonymous Korean newborn DBSs. Similarly, in our study, we did not detect any case of LSD in 12,559 DBS samples of asymptomatic subjects. Previous screening studies for LSDs using the MS/MS-based method are summarized in Table 6 [14, 27-33]. The cut-off values for enzyme activity vary considerably in other studies, the procedure employed for the analysis and LC-MS/MS conditions are different, as well as the method used to define the cut-offs.

The primary limitation of our study is that we could not report the incidence of LSDs in our national population since the number of subjects tested was small. The current method of analysis has to be used for screening a much larger number of samples to determine the exact prevalence of LSDs in India before implementing mass screening.

\section{Conclusion}

In conclusion, for the first time in India, we screened 12,559 putatively normal subjects for selected LSDs using an LC-MS/ MS-based method to simultaneously measure 5 lysosomal enzymes in DBS samples. With the availability of various treatment options for an increasing number of LSDs, newborn screening for LSDs could become a reality in India. The LC-MS/MS method for LSD screening is robust and may be readily integrated into existing facilities for the screening of symptomatic or sick children as well as for newborn screening programs.

Acknowledgement: This study was supported by the Department of Biotechnology (DBT) of the government of India. The authors gratefully acknowledge the technical support provided by Dr. P. Olivova and Dr. JM Keutzer, of Sanofi Genzyme Corp., USA. We also thank the Centers for Disease Control and Prevention Foundation, Atlanta, USA, for providing substrates, internal standards, and quality control specimens.

\section{Conflict of interest: None declared.}

Ethics Committee Approval: Study was approved by the Ethics Committee, National Institute of Mental Health and Neuro Sciences, Bengaluru, India (Basic Sciences, Item no III, SI No 3.01, dt 22-11-2011).

Financial Disclosure: None declared.

Peer-review: Externally peer-reviewed.

Authorship contributions: Concept - R.C.; Design - R.C.; Supervision - R.C.; Funding - R.C.; Materials - R.C., M.S., C.S.R.; Data collection \&/or processing - M.S., R.C.; Analysis and/or interpretation - R.C., M.S.; Literature search - R.C., M.S.; Writing - M.S., R.C., C.S.R.; Critical review - R.C., M.S., C.S.R.

\section{References}

1. Fletcher JM. Screening for lysosomal storage disorders--a clinical perspective. J Inherit Metab Dis 2006;29(2-3):405-8.

2. Vitner EB, Platt FM, Futerman AH. Common and uncommon pathogenic cascades in lysosomal storage diseases. J Biol Chem 2010;285(27):20423-7. [CrossRef]

3. Parkinson-Lawrence EJ, Shandala T, Prodoehl M, Plew R, Borlace GN, Brooks DA. Lysosomal storage disease: revealing 
lysosomal function and physiology. Physiology (Bethesda) 2010;25(2):102-15. [CrossRef]

4. Futerman $\mathrm{AH}$, van Meer $\mathrm{G}$. The cell biology of lysosomal storage disorders. Nat Rev Mol Cell Biol 2004;5(7):554-65. [CrossRef]

5. Desnick RJ. Enzyme replacement and beyond. J Inherit Metab Dis 2001;24(2):251-65. [CrossRef]

6. Prasad VK, Kurtzberg J. Transplant outcomes in mucopolysaccharidoses. Semin Hematol 2010;47(1):59-69. [CrossRef]

7. Abdi M, Hakhamaneshi MS, Alaei MR, Azadi NA, Vakili R, Zamanfar D, et al. Determination of Biological Variance and Validation of a Fluorometric Assay for Measurement of a-I-Iduronidase Activity in Dried Blood Spots Samples: The First Experience in Iran. Indian J Clin Biochem 2015;30(3):318-22.

8. Li Y, Scott CR, Chamoles NA, Ghavami A, Pinto BM, Turecek F, et al. Direct multiplex assay of lysosomal enzymes in dried blood spots for newborn screening. Clin Chem 2004;50(10):1785-96.

9. Gelb MH, Turecek F, Scott CR, Chamoles NA. Direct multiplex assay of enzymes in dried blood spots by tandem mass spectrometry for the newborn screening of lysosomal storage disorders. J Inherit Metab Dis 2006;29(2-3):397-404. [CrossRef]

10. Zhang XK, Elbin CS, Chuang WL, Cooper SK, Marashio CA, Beauregard $C$, et al. Multiplex enzyme assay screening of dried blood spots for lysosomal storage disorders by using tandem mass spectrometry. Clin Chem 2008;54(10):1725-8. [CrossRef]

11. Spáčil Z, Elliott S, Reeber SL, Gelb MH, Scott CR, Tureček F. Comparative triplex tandem mass spectrometry assays of lysosomal enzyme activities in dried blood spots using fast liquid chromatography: application to newborn screening of Pompe, Fabry, and Hurler diseases. Anal Chem 2011;83(12):4822-8.

12. Orsini JJ, Morrissey MA, Slavin LN, Wojcik M, Biski C, Martin M, Keutzer J, Zhang XK, Chuang WL, Elbin C, Caggana M. Implementation of newborn screening for Krabbe disease: population study and cutoff determination. Clin Biochem 2009;42(9):877-84. [CrossRef]

13. Marsden D, Levy $H$. Newborn screening of lysosomal storage disorders. Clin Chem 2010;56(7):1071-9. [CrossRef]

14. Liao HC, Chiang CC, Niu DM, Wang CH, Kao SM, Tsai FJ, et al. Detecting multiple lysosomal storage diseases by tandem mass spectrometry--a national newborn screening program in Taiwan. Clin Chim Acta 2014;431:80-6. [CrossRef]

15. Gelb MH, Scott CR, Turecek F. Newborn screening for lysosomal storage diseases. Clin Chem 2015;61(2):335-46. [CrossRef]

16. Matern D, Gavrilov D, Oglesbee D, Raymond K, Rinaldo P, Tortorelli S. Newborn screening for lysosomal storage disorders. Semin Perinatol 2015;39(3):206-16. [CrossRef]

17. Elliott S, Buroker N, Cournoyer JJ, Potier AM, Trometer JD, Elbin $C$, et al. Dataset and standard operating procedure for newborn screening of six lysosomal storage diseases: By tandem mass spectrometry. Data Brief 2016;8:915-24. [CrossRef]

18. Jack RM, Gordon C, Scott CR, Kishnani PS, Bali D. The use of acarbose inhibition in the measurement of acid alpha-glucosidase activity in blood lymphocytes for the diagnosis of Pompe disease. Genet Med 2006;8(5):307-12. [CrossRef]

19. Supriya M, De T, Christopher R. Age and gender-specific reference intervals for lysosomal enzymes in dried blood spot samples: A study in Indian population. Clin Biochem 2017;50(15):858-63. [CrossRef]

20. Evaluation of precision performance of quantitative measurement methods; approved guideline-second edition. Available at: https://yeec.com/uploadimages1/forum/2013-2/201321114424796191.pdf. Accessed Apr 15, 2020.

21. Wang RY, Bodamer OA, Watson MS, Wilcox WR; ACMG Work Group on Diagnostic Confirmation of Lysosomal Storage Diseases. Lysosomal storage diseases: diagnostic confirmation and management of presymptomatic individuals. Genet Med 2011;13(5):457-84. [CrossRef]

22. Verma IC. Burden of genetic disorders in India. Indian J Pediatr. 2000;67(12):893-8. [CrossRef]

23. Kadali S, Kolusu A, Gummadi MR, Undamatla J. The relative frequency of lysosomal storage disorders: a medical genetics referral laboratory's experience from India. J Child Neurol 2014;29(10):1377-82. [CrossRef]

24. Sheth J, Mistri M, Sheth F, Shah R, Bavdekar A, Godbole K, et al. Burden of lysosomal storage disorders in India: experience of 387 affected children from a single diagnostic facility. JIMD Rep 2014;12:51-63. [CrossRef]

25. Verma PK, Ranganath $P$, Dalal AB, Phadke SR. Spectrum of Lysosomal storage disorders at a medical genetics center in northern India. Indian Pediatr 2012;49(10):799-804. [CrossRef]

26. Agarwal S, Lahiri K, Muranjan M, Solanki N. The face of lysosomal storage disorders in India: a need for early diagnosis. Indian J Pediatr 2015;82(6):525-9. [CrossRef]

27. Mechtler TP, Stary S, Metz TF, De Jesús VR, Greber-Platzer S, Pollak $A$, et al. Neonatal screening for lysosomal storage disorders: feasibility and incidence from a nationwide study in Austria. Lancet 2012;379(9813):335-41. [CrossRef]

28. Wittmann J, Karg E, Turi S, Legnini E, Wittmann G, Giese AK,et al. Newborn screening for lysosomal storage disorders in hungary. JIMD Rep 2012;6:117-25. [CrossRef]

29. Burlina AB, Polo G, Salviati L, Duro G, Zizzo C, Dardis A, et al. Newborn screening for lysosomal storage disorders by tandem mass spectrometry in North East Italy. J Inherit Metab Dis 2018;41(2):209-19. [CrossRef]

30. Cho SE, Kwak JR, Lee H, Seo DH, Song J. Triplex tandem mass spectrometry assays for the screening of 3 lysosomal storage disorders in a Korean population. Clin Chim Acta 2016;454:20-7. [CrossRef]

31. Elliott S, Buroker N, Cournoyer JJ, Potier AM, Trometer JD, Elbin $C$, et al. Pilot study of newborn screening for six lysosomal storage diseases using Tandem Mass Spectrometry. Mol Genet Metab 2016;118(4):304-9. [CrossRef]

32. Burton BK, Charrow J, Hoganson GE, Waggoner D, Tinkle B, Braddock SR, et al G. Newborn Screening for Lysosomal Storage Disorders in Illinois: The Initial 15-Month Experience. J Pediatr 2017;190:130-5. [CrossRef]

33. Scott CR, Elliott S, Buroker N, Thomas LI, Keutzer J, Glass M, et al. Identification of infants at risk for developing Fabry, Pompe, or mucopolysaccharidosis-I from newborn blood spots by tandem mass spectrometry. J Pediatr 2013;163(2):498-503. 